\title{
The Roles of Urban Agriculture for Climate Change Adaption in The Case of Debre Markos Town and Surrounding Districts East Gojjam Zone Amhara Region Ethiopia
}

\author{
MENGIST BELAY \\ Department of Natural Resource Management, College of Agriculture and Natural Resource, Debre Markos \\ University, Ethiopia
}

\begin{abstract}
Rapid urbanization and large scale food production both heavily dependent on fossil fuels are arguably the most significant contributors to climate change. They are also increasingly recognized as potential tools in mitigation and adaptation to climate change. Climate change has already affected food production systems leaving loss of crop, grain shortages, and increased commodity price in its wake, all of which undermine food security a fundamental human right. This study establishes that Urban Agriculture is a multipronged tool for adaptation and mitigation to tackle climate change, and is the effective tool to address food security challenges in the cities, educate and reconnect urban and peri urban farms and people to assure food and climate security in the cities.
\end{abstract}

Keywords: Climate change; mitigation; adaptation; urban; peri urban.

DOI: $10.7176 / \mathrm{JEES} / 10-1-01$

Publication date: January $31^{\text {st }} 2020$

\section{INTRODUCTION}

Climate change is a serious concern today and researchers are affianced in understanding its impact on growth and yield of crops and also identifying suitable management options to sustain the crop productivity under the climate change scenarios. The variability of climatic factors brings fluctuations on crop yields [1]. According to IPCC climate change is any change in climate over time, whether due to natural variability or as a result of human activity. Studies of climate change impacts on agriculture initially focused on rising CO2 levels [2], but later it was reported that changes in temperature, radiation and precipitation etc. need to be studied to evaluate the impacts of climate change, beyond $\mathrm{CO} 2$ increase, on crops [3].

Urban population growth has a direct impact on this relationship between agriculture and climate change. Urbanization is an inescapable part of our economic growth models. We have now crossed the threshold of $50 \%$ of the world population living in cities [4]. Demographic analysis indicates that there are 70 million new urbandwellers each year, a large proportion of who live in developing countries. It is forecast that two thirds of the population will live in cities by 2025 . By 2015 about 26 cities in the world are expected to have a population of 10 million or more [5].

An estimated $40 \%$ of Africa's total population live in urban areas [6]. Although urbanization rates vary between and within countries or regions, literature shows a demographic shift toward an increasingly urban populous across the continent. The demographic change will have both social and environmental implications within urban areas and their resource providing regions [7]. Currently, only a modest proportion of net urbanization in Africa is related directly to climate and environment-induced migrations, but this is likely to increase in the future [8]. Already, some cities in the Sahel region, such as Dakar are experiencing higher net rural-urban migration due to weakened rural livelihoods exacerbated by a variable and changing climate [4]. Many city regions in Africa are experiencing or are at risk of sea level rise, storm surges, saline water intrusion, coastal erosion, floods, and droughts $[9,10,11]$. These impacts are likely to have implications for urban systems, urban infrastructure, public health, economic development, local environmental resources, food security, and water supplies and will affect disproportionately the vulnerable urban poor, women, elderly, and the young [2,12,13].

Cities have an important role to play in climate change mitigation and adaptation and enhancing climate resilience of their slum and vulnerable residents. Climate change adds to existing challenges faced by cities. Climate change, together with a decrease in absorption capacity of greenhouse gasses due reduction in the amount of green cover, parks, trees and agricultural surfaces in urban areas, poses serious threats to urban infrastructure, access to basic services and quality of life in cities and negatively affect the urban economy [5].

At the same time, rapid urban growth, growing urban poverty and increasing food prices raise concerns about urban food security, especially for the poor. Cities are highly vulnerable to disruption in critical (food) supplies and climate change exacerbates this vulnerability. For the current urbanization to be sustainable there is a need for "de-coupling" (enhancing the quality of life while minimizing resource extraction, energy consumption and waste generation and simultaneously safeguarding ecosystem services).

Decoupling will depend on how city-based energy, transportation, food, water and sanitation systems are planned and/or reconfigured. In this regard, there could be a role for Urban and Peri-urban Agriculture and Forestry 
(UPAF). UPAF was recognized by the World Bank as a potential strategy for recycling of organic waste and waste water; having potential energy saving benefits as local production reduces the need for transportation and refrigeration and having social benefits including better health and nutrition and livelihood opportunities [14].

Future urbanization trajectories pose both challenges and opportunities for addressing climate change impacts. While climate variability and environmental change impacts are well-documented in rural areas, literature is increasingly pointing to impacts in cities and their hinterland regions [3]. There are concerns about climate change impacts reinforcing poverty, exacerbating food insecurity and increasing vulnerability of urban populations $[3,15,16]$. Since urbanization exacerbates these vulnerabilities, there is growing evidence that urban and peri urban agriculture and forestry (UPAF) can play a role in poverty alleviation and potentially reduce vulnerability to climate change [17,18]. The relationship between poverty and UPAF has been well studied and emerging knowledge points to UPAF's potential to address climate risks [19,20].

Urban agriculture can help cities address climate change at the local level and prepare urban populations to deal with the challenges it brings. In addition to the many environmental, social, health, and economic benefits is has always brought to cities, urban agriculture now has a role to play as a climate change adaptation strategy. Increasing biologically productive green space will help to relieve the urban heat island effect, serve as a water management strategy, and enhance urban food security. In addition, urban agriculture will help to mitigate further climate change by reducing transportation needs and transforming the current agricultural practices that contribute to global warming. Mitigation remains a crucial aspect of addressing climate change because it reduces the magnitude of future calamities and the need for more drastic adaptation measures.

In Ethiopia, the impacts of climate change are obvious. They include the reduction of surface water level melting of glacier of Mount Ras Dejen and prolonged droughts and unpredictable rain cycles experienced in different parts of the country including Amhara Region [21,22]. Therefore, this paper reports on mitigation and adaptation measures undertaken by peri-urban farmers in mediating the effects of climate change in Amhara Region East Gojjam Zone, Debre Markos Town and surrounding areas.

The problem has been addressed through answering the following research questions: i) what is the level of adoption of mitigation and adaptation measures among peri-urban farmers? ii) which mitigation measures are applied by peri-urban farmers to mediate the impact of climate change? iii) which adaptation measures are implemented by peri-urban farmers against climate change?

\section{MATERIALS AND METHODS}

\subsection{The Study Area}

The study was done in Debre Markos Town and surrounding District in East Gojjam Zone, Amhara Region Ethiopia. The town is $300 \mathrm{kms} \mathrm{NW}$ of the capital, Addis Ababa and $265 \mathrm{kms}$ SE of Bahir Dar, the capital of Amhara National Regional State. It is geographically located at $10^{\circ} 20^{\prime} \mathrm{N} 37^{\circ} 43^{\prime} \mathrm{E} / 10.333^{\circ} \mathrm{N} 37.717^{\circ} \mathrm{E}$ with an average altitude of $2446 \mathrm{~m}$ above sea level. It has conducive weather condition with $1380 \mathrm{~mm}$ average annual rainfall and $18^{\circ} \mathrm{c}$ average annual temperature. According to the municipality's report, the town has over 123,000 residents of which 97 percent are Amhara and the remaining three percent are from Agaw, Oromo, Tigre and others nations. Although there are various religions (orthodox Christians, Muslims and Evangelical Christians), most of the dwellers are Orthodox Christian.

Economic activities carried out in Debre Markos and surround district include farming, businesses as well as wages employment. The main sources of income among the local communities include; farming, sales of food crops, forest products, livestock and associated products. The study used a cross sectional research design to examine existing mitigation and adaptation measures across four selected peri-urban wards Debre Markos town and surrounding District. This design was opted due to the fact that it allows data to be collected at a single point in time [1].

\subsection{Study Method}

The study was conducted in five villages representing three agro-ecological zones: Highland (Yegagina and Enarata), midland (Debre Markos and Wenqa) and lowland (Qebie). Rainfall data were acquired from the National Meteorological Agency. Agricultural (vegetables and livestock) development trend information was collected based on historical event time line (Nyssen et al. 2006) in which farmers can easily remember the study years. These years were 1984/5, 1986, 1989, 1994, 1998, 1999, 2002, 2005 and 2007.

In total, 140 household heads were selected for the purpose. Data collected from the questionnaire survey, meteorological data and other secondary sources were analyzed using Microsoft Office EXCEL (2003) software. 


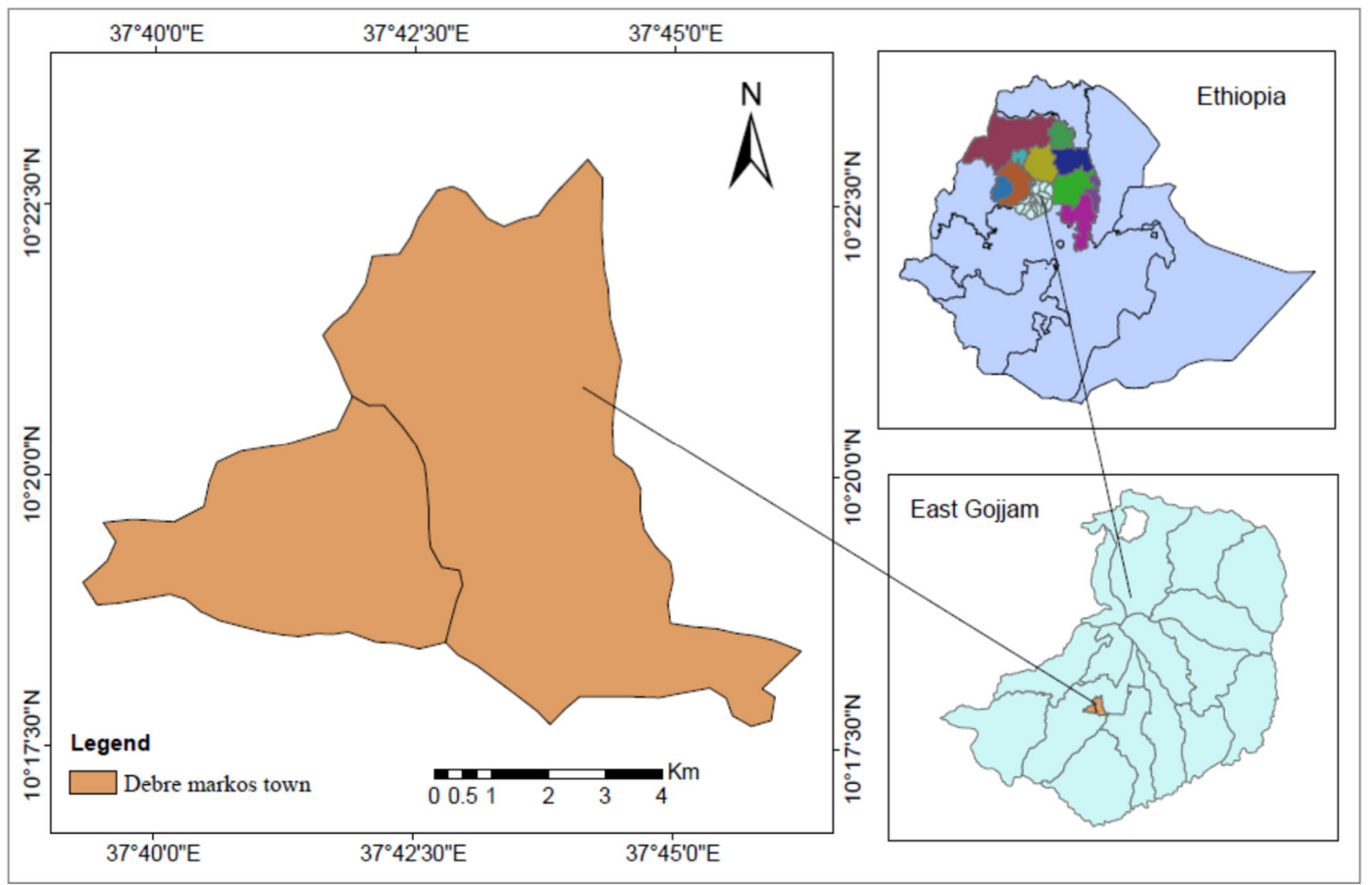

Fig. 1. Map of study area

\section{RESULTS AND DISCUSSION}

\subsection{Selected Socio-economic and Demographic Characteristics of the Respondents}

Socio-economic and demographic characteristics were assessed to reveal the baseline information of the characteristics of interest of the study population. These characteristics are presented in The findings show that $59.2 \%$ of the respondents were males while $40.8 \%$ were females. In terms of the age groups $21-34$ years comprised of $25.42 \%, 35$ - 59 years $61.66 \%$ while $12.92 \%$ were respondents with 60 years and above. The mean age was 43.33 indicating that majority of the farmers were more energetic and that they are likely to devote to more time on farming besides other economic activities. Of all the respondents, $68.8 \%$ indicated that they had completed primary education, $5.4 \%$ had secondary education while less than $1 \%$ had ordinary certificates attained upon completion of form four. In terms of occupation, $49.2 \%$ were farming, while 48.3 were also doing commercial activities in addition to farming. Based on the findings, PUF is more practiced by middle age people and with low education level. About $88 \%$ of the respondents owned land and about $13 \%$ either rented or were permitted by land owners to use for farming.

Table 1. Socio economic and demographic characteristics of the respondents $(n=240)$

\begin{tabular}{ll}
\hline Education & Percent \\
\hline No formal education & 12.9 \\
Primary & 68.8 \\
Secondary & 5.4 \\
Ordinary certificates & 0.4 \\
Adult education & 12.5 \\
Total & $\mathbf{1 0 0}$ \\
\hline Occupation & \\
\hline Farming only & 49.2 \\
Farming with petty business & 48.3 \\
Formal employment with farming & 2.5 \\
Total & $\mathbf{1 0 0}$ \\
\hline
\end{tabular}

\subsection{Rainfall Variability and Trends}

The average annual rainfall in the study area ranged from $1380 \mathrm{~mm}$, with wide temporal and spatial variation. The spatial variation was high, with the highest standard deviation in the lowlands. The lowest deviation was, however, observed in the midlands. The midlands, which cover the largest portion of the study area, also showed a slightly decreasing rainfall pattern over the study periods.

This corresponds with the study of Jan, S. Anja, B. [23] who observed that there was a decreasing trend in the 1980s and a slightly above average trend in the years after 1990. Similar to the study in other parts of northern 
Ethiopia [24], this study showed that the rainfall pattern was perceived to have changed over the past decades, particularly in terms of timing and duration. There have also been reports of rainfall variability and drought associated food shortages [25]. The rainfall pattern was extremely unpredictable and erratic with a coefficient of variation ranging from 18 percent in the midlands to 42 percent in the lowlands. This corresponds with the findings of Kurukulasuriya, P. and Mendelsohn, R. [26], in northern Ethiopia, who found a coefficient of variation more than 30 percent. According to the inhabitants, except in more dry years, changes in seasonality and distribution regularity of rainfall were more of a concern than the overall amount of rainfall.

\subsection{Vegetable Production Trend}

Elders indicated that the changes became more noticeable since the major famine in 1984/85. They felt that the main rainy season was becoming progressively shorter. Moreover, it started late and ceased earlier than it used to. This is in agreement with the rainfall data obtained from national meteorological records. Elders associated the variability with vegetables growing periods by noting that in the past people could see fully germinated vegetables up to the 12th of July and matured vegetables up to the 22nd of August. However, the rains which normally used to start in mid-June, shifted to July and ceased much earlier than was normally the case, which stretched to midSeptember. In most of the months, $0 \mathrm{~mm}$ rainfall was recorded.

The variation in rainfall among months in each site and each year was very high. As water shortage was already a major development challenge in the study villages, the uneven and erratic nature of the rains will exacerbate the existing problem of drought and land degradation [27] in the midlands in particular. Elders indicated that several traditional vegetables had been lost in the area and several were introduced.

In addition to the major vegetables, many local vegetables such as cabage, qousta, selata and tomato are grown. Each variety were introduced by Bureau of Agriculture and Rural Development. These varieties have gained wide acceptance and are widely grown replacing mono cropping. However, the vegetable sping of oats declined and teff sown during the dry-season has become practically abandoned. A study by Kiunsi, R. [28] in a village in southeastern Tigray also compared the agricultural calendar from $1930-1950$ with the present agricultural calendar. They found a tendency towards fewer vegetables varieties and shifting to a shorter planting season, indicating that most vegetables are planted during mid- to end of June, and are often harvested some weeks earlier as well.

The preference of farmers to new varieties, short growing cycle vegetables with good production, contributed to the reduced vegetables diversity. The average vegetables production in the highlands showed a positive trend ( $\mathrm{R}=0.43$ in Debre Markos and $\mathrm{R}=0.11$ in Wenqa). The yield of cabbage in Yigagina village showed a slight but not significant increase. Miscellaneous vegetables in the village had a strong positive correlation with time $(\mathrm{R}=$ $0.74)$. The yield of qosta and selata in the village Qebie showed a significant difference. Both showed a negative trend $(\mathrm{R}=-0.58)$. However, the yield of tomato, pottato and onion significantly increased with $\mathrm{R}$ values of 0.72 , 0.48 and 0.49 , respectively. In addition, the climate and vegetable data shows that there was a general perception among rural households that vegetables production and land productivity declined in the past 20 or so years $(\mathrm{R}=$ -0.17 in Debre Markos and $R=-0.47$ in Yegagina). Similar studies $[29,30,31]$ in other parts of Ethiopia estimated a total loss of annual food production over some areas, while in other areas the loss was as high as 50 percent.

The yield of all major vegetables grown in Wenqa village showed a decreasing trend. However, only mono cropping and chickpea showed a significant difference with $\mathrm{R}$ value of $-0.69,-0.51$ and -0.49 , respectively. The yield of tomato, pottato and onion in Debre Markos showed a slight increase with time but not significantly different. However, a significant difference was observed only in the yield of broad bean and sorghum. Both showed a negative trend with $\mathrm{R}$ values of -0.7 and -0.6 , respectively. The yield of all major vegetables grown in the selected sample village showed a positive trend $(\mathrm{R}=0.43)$.

\subsection{Climate Change and Vegetables Production}

Historically, the study area was affected by many drought events. The drought in 1984/85 was the worst. The change in rainfall distribution and pattern had contributed to the change in vegetable sping pattern and vegetables yield. The study showed a positive correlation between rainfall and vegetables yield in four of the survey villages. Only the Kebie village showed a negative correlation between rainfall amount and vegetables yield. Overall, the coefficient of correlation between rainfall amount and vegetables yield is very small. The lower response of rainfall to vegetables yield could be due to the seasonal variability of rainfall rather than the amount and other nonclimatic factors, which needs further investigation.

\subsection{Climate Change and Farmers' Adaptive Mechanisms}

Among adaptations made in response to climate change, planting different varieties of the same vegetables and changing planting dates were important everywhere. The study assessed the level of adoption of mitigation and adaptation in order to ascertain an overview of the farmers ${ }^{e e}$ initiatives to address climate change at the contextual level. In terms of mitigation measures, the findings reveal that $60.8 \%$ of the respondents had the highest level of 
adoption, $32.5 \%$ had medium level and $6.7 \%$ had the lowest level. This indicates that the level of mitigation measures pursued by the households in mediating climate change is reasonably high.

This is because most of farmers use more than one mitigation measure to mediate climate change effects. Equally, this implies that local level initiatives are not helpless in the bid to reduce global greenhouse gas emissions. The level of adoption of mitigation measures was correlated with the age groups. Results from a Kruskal Wallis Test suggest statistically significant difference in the level of adoption of mitigation measures across three groups at $\mathrm{p}<0.05$. As observed in the table, mean ranks for the groups suggest that the older group (60 years and above) had the highest level of adoption with the younger group reporting the lowest level of adoption. The possible reason for the findings is that the older farmers are more likely to engage in activities which translate to mitigation than the younger farmers.

Similar to the findings of Ringo, J. et al. [32], and Ricci, L. [33], the vegetables mixes selected by farmers differed depending on whether conditions were dry, medium wet, or wet. The findings in this paper suggested that as precipitation increases or decreases, farmers will shift toward water-loving or drought-tolerant vegetables.

Farmers also responded to reduced soil fertility by implementing vegetables management strategies in addition to their management by organic and inorganic fertilizer application. Common vegetables management strategies were sowing vegetables based on the nutrient status of the soil. Moreover, farmers in all villages employed rotational vegetable sping to restore soil fertility. Few farmers applied manure in nearby fields and the use of compost was wide spread. No fallowing was practiced due to shortage of farm land. Instead, they grew grass pea or chick pea to restore fertility and reduce weed infestation. Similar to studies elsewhere [34], poor households were forced to change their normal food intake and adjusted their consumption during acute drought periods so that they could easily adapt to the resources at hand. This included reduction in variety of food consumed, cut meal size and number, postponement of special functions such as marriage and festivals, reducing expenditures on other household goods and eating inexpensive foods.

Relying on wild fruits and vegetables was a common phenomenon in the study villages. The commonly used wild food types were Opuntia ficus-indica, Caralluma penciliata and Brassica nigra. Moreover, they looked for fruits of Carissa edulis and Ficus vista (in the highlands); Cordia Africana (in the midlands); Ziziphus spina-christi and Diospyros mespliformis (in the lowlands). Food relief provided by the government in the form of food for work was the main drought copping mechanism in all study villages. About 80 percent of the elders reported the use of reserve seeds, past cash savings, and barter exchange with neighbors and relatives. Borrowing food from merchants, purchase food stuff on credit from traders, getting credit from money lenders and participating in small petty trading were other drought copping strategies. Withdrawing children from school was also a common drought copping strategy in the study sites. To reduce school withdrawal, the government in collaboration with the World Food Programme served school children with feeding programme.

\section{CONCLUSION}

Urban Agriculture is no longer a romantic option. It is a necessity to address the climate challenge that humanity is facing. Urban Agriculture has a huge advantage in adopting the newer sustainable technologies that are coming down the pipeline as observed by Jay Salinas of Growing Power. Urban agriculture presents our society with a range of opportunities from waste management to food production in a zero waste cycle. Choices that integrate UA into the fabric of urban landscapes have the potential to deliver resilience in economic, social and environmental terms, to reinforce the local It is critically important that UA be engaged in its many forms where it is appropriate, with the focus on strengthening community based regional agriculture.

With UA we witness a step away from corporate agriculture and a step toward community based regional agriculture. Urban Agriculture is important for its productive acreage but it is more important from the perspective of transforming urban dwellers from being consumers into a community of co-producers. By participating in UA, people can develop a deeper understanding for food and respect for the farmers who dedicate their lives to growing it. By networking with local farms in 150 mile radius cities can become resilient, powerful by being locally adapted to the regional food system. Cities can move towards zero waste goals by using UA to utilize the organic fertility generated by the city. The 'waste' will be captured and kept within the regional system in form of carrying capacity of the region. Urban Agriculture is also an economic and social tool which in very simple ways will provide employment opportunities, opportunities for social networking and working together as a community. It will reduce the carbon footprint of city dwellers and decrease their dependence on fossil fuels. Urban Agriculture is a significant tool that if wielded properly, will help us cope with climate change and food insecurity. While search for that is on, we already have an option to reduce our dependence on fossil fuel, by adapting UA. As Mr. Will Allen of Growing Power said (Miner, 2008), "We have to go back to when people shared things and started taking care of each other, that's the only way we will survive." "What better way than to do it with food?"

\section{REFERENCES}

1. Gündel S. A synthesis of urban and peri-urban agricultural research. Final Report. Edinburg, Britain; 2006. 
2. Ishaya S, Abaje IB. Indigenous people ${ }^{\text {ee }}$ s perception on climate change and adaptation strategies in Jemma LGA of Kaduna State. Journal of Geography and Regional Planning. 2008;1(18):138-143.

3. Mysha Clarke, Melissa Davidson, Monika Egerer, Elsa Anderson. The underutilized role of community gardens in improving cities' adaptation to climate change: A review. People, Place and Policy: Villanova University; 2019.

4. Lema MA, Majule AE. Impacts of climate change, variability and adaptation strategies on agriculture in semiarid areas of Tanzania: The case of Manyoni District of Singida Region, Tanzania. African Journal of Environmental Science and Technology. 2009;3(8):206-218.

5. Dungumaro EW, Hyden G. Challenges and opportunities to climate change adaptation and sustainable development among Tanzanian rural communities. Proceedings of an International Conference on Climate, Sustainability and Development in Semi-Arid Regions. Fortaleza, Ceara Brazil. 16 - 20 August; 2010.

6. Lyimo JG, Kangalawe RYM. Vulnerability and adaptive strategies to climate change and variability. A case of rural households in semi Arid-Tanzania. Journal of Environmental Economics. 2010;1(2).

7. Lunyelele SP, Bengesi KMK, Katani JZ. Awareness of peri-urban farmers on the concept of climate change: A case of Debre Markos town and surrounding district, Dar es Salaam Region. Journal of Environment and Earth Science. 2016;6(7):24-34.

8. Lobell DB, Marshall B. Food security and adaptation to climate change: What do we know? In: Climate Change and Food Security Adapting Agriculture to a Warmer World. (Edited by Lobell, D. B. and Marshall, B.), Dordrecht, New York: Springer. 2010;133-154.

9. Intergovernmental Panel for Climate Change. Climate change: Synthesis report summary for policymakers. Workgroup Contribution to the Fourth Assessment Report at IPCC Plenary, XXVII. 2007;12-17.

10. Intergovernmental Panel for Climate Change. Climate Change 2001: Impacts, adaptation, and vulnerability. In J. J. Mc Carthy, O. F. Canziani, N. A. Leary, D. J. Dokken and K. S. White (Eds.), Contribution of Working Group II to the Third Assessment Report of the Intergovernmental Panel on Climate Change. Cambridge: Cambridge University Press. 2001;1032.

11. Kashaigili JJ, Levira P, Liwenga E, Mdemu MV. Analysis of climate variability, perceptions and coping strategies of Tanzanian coastal forest dependent communities. American Journal of Climate Change. 2014;3:212-222.

12. Kalungu JW, Filho WL, Harris D. Smallholder farmerse perception of the impacts of climate change and viability on rain-fed agricultural practices in semi-arid and sub-humid regions of Kenya. Journal of Environment and Earth Science. 2013;3(7):129-140.

13. Kandji ST, Verchot LV, Mackensen J, Bantilan C, Anupama KV, Palm C. Climate change: Linking adaptation and mitigation through agroforestry. Mitigation Adaptation Strategies Global Change. 2007;12:901-918.

14. Dubbeling M. Cities, climate change and urban agriculture: The potential contributions of urban and peri urban agriculture and forestry (UPA/F) to climate change adaptation and mitigation. Proceedings of RUAFCAH Conference, Almere 19-20 May; 2011.

15. Blaike P, Cannon T, Davis I, Wisner B. At risk: Natural hazards, peoples vulnerability, and disasters. London, Routledge; 1994.

16. Blaikie P. Vulnerability and disasters. In Desai, V. and Potter, R. (Eds.), Companion to Development Studies. Oxford University Press and 198 Madison Avenue, New York; 2002.

17. Babbie E. Survey Research Methods ( $2^{\text {nd }}$ Ed). Belmont, USA: Cengage Lerning; 1990.

18. Barthes B, Azontonde A, Blanchart E, Girardin C, Villenave C, Lesaint S, Oliver R, Feller C. Effect of legume cover crop (Mucuna pruries var. utilis) on soil carbon in an Ultisol under maize cultivation in southern Benin. Journal of Soil Use Management. 2004;20:231-239.

19. Adger NW, Amell NW, Tompkins EL. Successful adaptation to climate change across scales. Global Environmental Change. 2005;15:77-86.

20. Antrop M. Changing patterns in the urbanised countryside of Western Europe. Landscape Ecology. 2000;15(3):257-270.

21. Havaligi N. Climate change and food security in cities. World Bank Fifth Urban Research Symposium. $2009 ; 1-16$.

22. Idrisa YL, Ogunbameru BO, Ibrahim AA, Bawa DB. Analysis of awareness and adaptation to climate change among farmers in the Sahel Savannah Agro-ecological Zone of Borno State, Nigeria. British Journal of Environment \& Climate Change. 2012;2(2):216-226.

23. Jan S, Anja B. Indigenous peoples and climate change. University of Oxford and Missouri Botanical Garden; 2007.

24. Kassenga G, Mbuligwe S. Report on investigation of Dar es Salaames institutional activities related to climate change; 2012. [Online]Available:http.//www.planning4adaptation.eu/(May 18, 2016).

25. Kihupi ML, Mahonge C, Chingonikaya EE. Smallholder farmers ${ }^{e e}$ adaptation strategies to impact of climate 
change in semi-arid areas of Iringa District Tanzania. Journal of Biology, Agriculture and Healthcare. 2015;5(2):123-132.

26. Kurukulasuriya P, Mendelsohn R. Crop selection: Adapting to climate change in Africa. Centre for Environmental Economics and Policy in Africa (CEEPA), Discussion Paper No. 26, University of Pretoria, Pretoria. 2006b;28.

27. Komirenko Z, Hoermann DM. Urban and peri-urban agriculture in Kyiv (Ukraine): Crisis induced strategy versus recreational resource. A Paper Presented in $12^{\text {th }}$ Congress of the European Association of Agricultural Economists. 2008;1-5.

28. Kiunsi R. The constraints on climate change adaptation in a city with a large development deficit: The case of Dar es Salaam. Journal of Environment and Urbanization. 2013;25(2):321-337.

29. Oruonye ED. An assessment of the trends of climatic variables in Taraba State, Nigeria. Global Journal of Science Frontier Research. 2014;14(4).

30. Opio C, Gerber P, Mottet A, Falcucci A, Tempio G, MacLeod M, Vellinga T, Henderson B, Steinfeld H. Greenhouse gas emissions from ruminant supply chains - A global life cycle assessment. Food and Agriculture Organization of the United Nations (FAO), Rome. 2013;21-24.

31. Nair PKR. An introduction to agroforestry. London, Kluwer Academic Publishers, London; 1993.

32. Ringo JJ, Bengesi KMK, Mbago MCY. Gender determined roles and under-five mortality among agropastoralist; 2018a.

33. Ricci L. Peri-urban livelihood and adaptive capacity: urban development in Dar es Salaam. The Journal of Sustainable Development. 2012;7(1):46-63.

34. Adger WN, Vincent K. Uncertainty in adaptive capacity (IPCC Special Issue on Describing Uncertainties in Climate Change to Support Analysis of Risk and Options), Comptes Rendus Geoscience. 2005;337(4): 399410. 